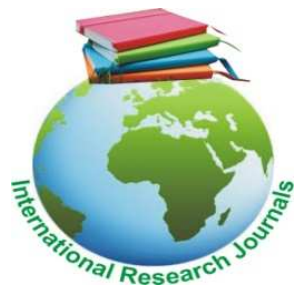

Journal of Medicine and Medical Sciences Vol. 7(3) pp. 042-046, May 2016

Available online http://www.interesjournals.org/JMMS

DOI: http:/dx.doi.org/10.14303/jmms.2016.305

Copyright (C) 2016 International Research Journals

Full Length Research Paper

\title{
Traumatic tympanic membrane perforations: Management outcomes in a resource poor Country
}

\author{
*Onotai L.O and Oghenekaro E.N \\ Department of E.N.T Surgery, U.P.T.H. Port Harcourt \\ *Corresponding Author's Email: onotailuckinx@yahoo.co.uk
}

\begin{abstract}
Background: Traumatic tympanic membrane perforations (TTMP) occur commonly in our setting which is a very busy Metropolitan city. Its management can be quite challenging to the otolaryngologists because of late presentation. This study determines the prevalence of TTMP, highlights the etiological factors and management outcome as seen in Port Harcourt, Nigeria. Patients and Methods: A prospective study of 35 patients clinically diagnosed to have TTMP out of 1,257 patients with aural diseases at the Ear Nose and Throat (ENT) surgery clinics of University of Port Harcourt Teaching Hospital (UPTH) and Kinx Medical Consultants clinic in Port Harcourt, between January 2014 to December 2014. Information obtained from the patients was documented in a pro-forma prepared for the study. The information collected were bio-data, clinical presentations, otoscopic findings, pure tone audiometry findings, source of injury, complications and management outcome. The data were analyzed descriptively and illustrated with simple statistical tables and pie chart. Results: Traumatic tympanic membrane perforation prevalence was found to be $2.78 \%$. Age range was 2-70 years with a mean age of 35.2 years \pm 6.3 . The commonest age group affected was $35-45$ years; the male to female ratio was 1:1.3. Commonest etiological factor was slap on the ear. Bleeding from the ear was the commonest symptom. The commonest otoscopic finding was blood clots in the external auditory canal with central tympanic membrane perforation. The commonest complication encountered was Chronic Suppurative Otitis Media. Fourteen patients responded to treatment after 1 month of conservative management. Conclusion: Slap on the ear ranked highest as etiological factor. Forty percent of the patients responded to treatment after 1 month of conservative management.
\end{abstract}

Keywords: Trauma, Tympanic membrane, perforation, Management outcome, Resource poor Country

\section{INTRODUCTION}

Tympanic membrane perforation is a condition as old as the human species (Benitez, 1988). Apart from trauma it can result from disease processes, for example poorly treated acute otitis media and otitis media with effusion. Perforation can be temporary which means it can heal within 2 weeks or 1 month of conservative treatment and remain persistent despite conservative management for over 6 weeks. The outcome of management varies with size, location on the tympanic membrane surface, and associated pathologic condition (Afolabi et al., 2009).

Traumatic perforations can occur from blows to the ear, severe excessive atmospheric pressure, exposure to excessive water pressure and improper attempts at wax removal or ear cleaning with cotton buds. Inexpertly performed syringing of the ear canal for wax removal can lead to perforation. In some settings, when irrigation for cerumen is relegated to medical assistants, otolaryngologists may see 10-20 patients per year with this injury because of inexperience (Afolabi et al., 2009). Evidence exists that such perforations are less likely to heal spontaneously because of the big size and in some cases the blood clots which can help seal the defect are removed during the irrigation (Orji and Agu, 2008).

Tympanic membrane perforation is intentionally created whenever a surgeon carries out myringotomy procedure and when pressure-equalizing tubes are placed. The failure of surgically created openings to heal when the tube extrudes, results in chronic tympanic 
Table 1: Age range of the patients

\begin{tabular}{lcc}
\hline Age range (years) & Number & Percentage (\%) \\
\hline $2-12$ & 7 & 20.00 \\
$13-23$ & 4 & 11.43 \\
$24-34$ & 5 & 14.26 \\
$35-45$ & 10 & 28.57 \\
$46-56$ & 4 & 11.43 \\
$57-67$ & 3 & 8.57 \\
68 and above & 2 & 5.71 \\
Total & $\mathbf{3 5}$ & $\mathbf{1 0 0 . 0 0}$ \\
\hline
\end{tabular}

membrane perforation (Chun et al., 1999). Other etiological agents could be trauma from assaults, road traffic accidents, domestic accidents, industrial and sports accidents.

The patient may report audible whistling sounds during sneezing and nose blowing, decreased hearing, and when water enters the ear canal. Some patients may develop bleeding from the ear canal, tinnitus, and vertigo. Diagnosis is based on the history and otoscopic findings. Treatment often is unnecessary. Antibiotics may be needed for infection. Surgery may be needed for perforations persisting for more than 3 months.

The goal of medical therapy for perforations is preventing infection and achieving good tympanic membrane healing. Keeping the affected ear dry is the main stay of treatment. Once there is otorrheoa, topically applied eardrops like gentamicin into the ear canal of a patient with traumatic tympanic membrane perforation carry the risk of poor healing of the membrane and ototoxicity. However, microscopy, culture and sensitivity result can be used to select the antibiotics which are sensitive to the organisms responsible for the ongoing infection to control the otorrhea from a tympanic membrane perforation (Onyeagwara et al., 2014; da Lilly Tariah and Somefun, 2007).

In-office treatments for TTMP that failed to response to conservative medical treatment include the paperpatch method. A Gelfoam plug in combination with surgical removal of the perforation edges, and fibrin glue or a patch composed of a hyaluronic acid ester and a dressing component can also be used in the surgical management of TTMP (Onyeagwara et al., 2014; Lerut et al., 2012; Dursun et al., 2008). A review of literature shows that there is paucity of information on TTMP in our setting. Therefore, this study determines the prevalence of TTMP, highlights the etiological factors and management outcome as seen in Port Harcourt, Nigeria.

\section{PATIENTS AND METHODS}

A prospective (January 2014 to December 2014) study of 35 patients clinically diagnosed at ENT surgery clinics of
UPTH and Kinx Medical Consultants clinic in Port Harcourt. All the patients were evaluated by the otolaryngologist. Only patients with history of various trauma to the ear were recruited for this study. Data obtained from the patients were documented by the researchers in a pro-forma (Appendix 1) prepared for the study. Ethical approval was given for this study. The data recorded were bio-data (age and gender), clinical presentations, time spent before presentation, otoscopic findings, pure tone audiometry findings, source of injury, complications and management outcome. The data were entered into SPSS version 14 computer software and analyzed descriptively.

\section{RESULTS}

Thirty five patients were found to have TTMP out of 1,257 patients with various aural diseases that were seen during the study period giving a prevalence of $2.78 \%$. Age range was 2- 70 years with a mean age of 35.2 years \pm 6.3 . The male to female ratio was $1: 1.3$ and the commonest age group affected was 35-45 years (Table 1). Majority $n=20(57.14 \%)$ of the patients spent more than 72 hours before presenting to the hospital while 15 (42.86\%) patients presented before 72 hours.

The commonest etiological factor was from slaps $n=15$ (42.86\%), followed by cotton bud injury $n=10,(28.57 \%)$ (Table 2). The slap injuries were from security agents $n=8,(22.86 \%)$ and domestic assaults $n=7$ (20.00\%).

The clinical findings revealed that bleeding from the ear was the commonest $n=15 \quad(42.86 \%)$ mode of presentation (Table 3). Some of the patients $n=12$, (34.29\%) had first aid treatment in the chemist shops prior to presentation to the hospital due to ignorance and poverty. The left ear $n=19(52.29 \%)$ was more affected than the right. The commonest otoscopic finding was blood clots in the external auditory canal with central tympanic membrane perforation $n=15$, (42.86\%) (Table 4).

The commonest $n=6, \quad(17.14 \%)$ complication encountered was Chronic Suppurative Otitis Media. Only $14(40 \%)$ patients responded to treatment after 1 month 
044 J. Med. Med. Sci.

Table 2: Etiological factors

\begin{tabular}{lcc}
\hline Etiological factor & Number & Percentage (\%) \\
\hline Slap on the ear & 15 & 42.86 \\
Trauma from the use of cotton bud & 10 & 28.57 \\
Road traffic accident & 4 & 11.43 \\
Trauma during removal of foreign body from the ear & 6 & 17.14 \\
Total & $\mathbf{3 5}$ & $\mathbf{1 0 0 . 0 0}$ \\
\hline
\end{tabular}

Table 3: Mode of clinical presentation

\begin{tabular}{lcc}
\hline Clinical presentation & Number & Percentage (\%) \\
\hline Bleeding from the external Auditory canal & 15 & 42.86 \\
Mucopurulent discharge from the external auditory canal & 6 & 17.14 \\
Hearing impairment & 4 & 11.43 \\
Otalgia & 5 & 14.29 \\
Tinnitus & 5 & 14.29 \\
Total & $\mathbf{3 5}$ & $\mathbf{1 0 0 . 0 0}$ \\
\hline
\end{tabular}

Table 4: Otoscopic findings

\begin{tabular}{lcc}
\hline Otoscopic finding & Number & Percentage (\%) \\
\hline Central tympanic membrane perforation with blood clots & 15 & 42.86 \\
Marginal tympanic membrane perforation with blood clots & 8 & 22.86 \\
Postero superior tympanic membrane perforation & 6 & 17.14 \\
Antero inferior tympanic membrane perforation with muco- & 4 & 11.43 \\
purulent discharge & 2 & 5.71 \\
$\begin{array}{l}\text { Subtotal tympanic membrane discharge with muco- } \\
\text { purulent discharge }\end{array}$ & $\mathbf{3 5}$ & $\mathbf{1 0 0 . 0 0}$ \\
Total
\end{tabular}

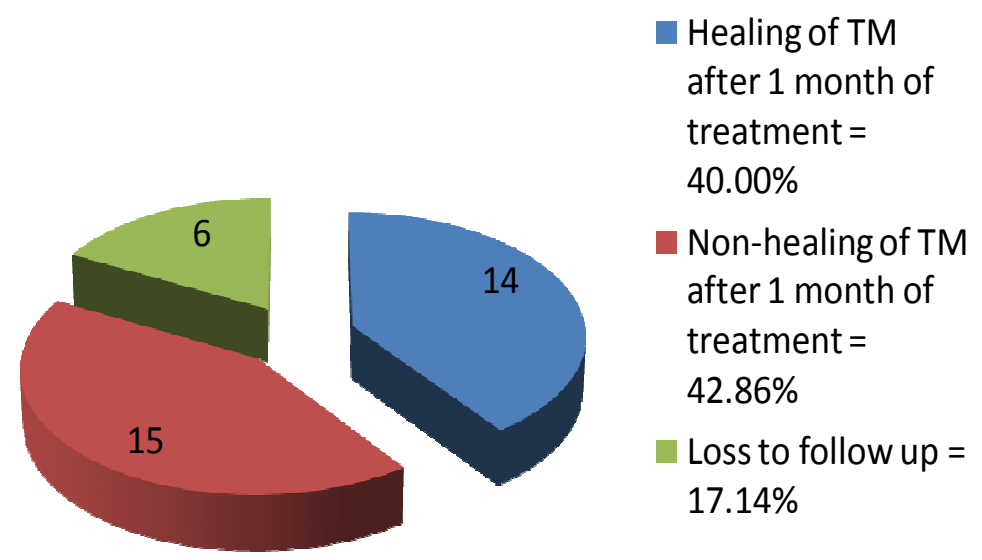

Figure 1: Outcome of treatment after 1 month

of conservative management, with antibiotic oral medications and vitamin c and analgesics. Six (17.14\%) patients were lost to follow up (Figure 1). The few patients with hearing loss were managed successfully. 
The tympanic membranes of 15 patients that failed to heal were referred to centres that have facilities and expertise for surgical management

\section{DISCUSSION}

Traumatic tympanic membrane perforations in this study have a prevalence of $2.78 \%$ of cases seen at the ENT clinic of UPTH and Kinx Medical Consultants clinic in Port Harcourt. This finding gives the impression that there is a reduction in the prevalence of traumatic tympanic membrane perforations in Port Harcourt because a previous work done by da Lilly Tariah and Somefun in 2007 revealed a prevalence of $8.6 \%$ (da Lilly Tariah and Somefun, 2007). This may not actually be the case since the duration of the previous study was more than the duration of this study. Besides, the number of aural diseases seen during this study period was smaller.

The commonest age group involved in traumatic ear perforation in our series was 35-45years which accounted for $28.57 \%$ of cases seen. Afolabi et al, found age group 21-34 years to be the commonest with $29.7 \%$ (Afolabi et al., 2009) while Onyeagwara et al reported the age group 18-34 years (65.5\%) as the commonest (Onyeagwara et al., 2014). Thus young adult seemed to be the most affected. The reason could be that they are either more involved in violet activities or more involved in road traffic accidents.

In this study, traumatic tympanic membrane perforation was found to be commoner in females (57.14\%), Sarojamma et al., reported similar findings of more females $(58.0 \%)$ than males (Sarojamma et al., 2014). Afolabi et al., reported more males (71.9\%) than females (Afolabi et al., 2009), while Zhen-cailou et al reported equal distribution (Zheng et al., 2012).

Majority of the patents presented to the hospital for expert management after 72 hours of sustaining the ear injury. The reason for the late presentation could be attributed to ignorance, poverty and lack of nearby specialist centres. These reason have also been highlighted by other researchers (Afolabi et al., 2009; Orji and Agu, 2008).

The commonest aetiological factor was slaps on the ear $(42.86 \%)$, followed by cotton bud injury while the patients were cleaning their ears $(28.57 \%)$. This finding was similar to works by Onyeagwara et al., who reported slaps (57.5\%) (Onyeagwara et al, 2014) and Afolabi et al., who reported slaps (35.9\%) and cotton bud (10.9\%) (Afolabi et al., 2009). However, Salim in Iraq reported blast injury as commonest cause, followed by slap $27.5 \%$ and foreign body instrumentation $11.0 \%$ (Salim, 2009).

Bleeding from the ear accounted for $42.86 \%$ and was the commonest clinical presentation, followed by mucopurulent discharge from the ear $17.14 \%$. This varies from the findings of Afolabi et al, who reported hearing loss $(95.3 \%)$ as the commonest symptom followed by bleeding (68.8\%) (Afolabi et al., 2009). Several other studies also reported hearing loss as the commonest symptom (da Lilly Tariah and Somefun, 2007; Onyeagwara et al, 2014). In our study only 4 (11.43\%) patients had hearing impairment.

Blood clot in the external auditory canal with central perforation accounted for $42.86 \%$ of the cases seen. These findings differ from the findings of Salim who reported blood clots in the external auditory canal with posterior perforation as the commonest (Salim, 2009) and that of Sarojamma et al., who recorded blood clots in the external auditory canal with perforation of the postero-inferior quadrant of the tympanic membrane as the commonest (Sarojamma et al., 2014).

This study revealed that the left ear (54.29\%) was more affected than the right ear $(45.71 \%)$, with no case of bilateral perforation seen in our series. This is in keeping with Afolabi et al., and Sarojamma et al., who recorded similar findings (Afolabi et al., 2009; Sarojamma et al., 2014). Left ear being commonly affected is likely due to the fact that most people are right handed thus the left ear is more prone to injury from slaps by right handed people (Afolabi et al., 2009).

The commonest complication was chronic suppurative otitis media (CSOM) seen in $17.14 \%$ of cases.. Onyeagwara et al., however reported a lower incidence of CSOM (9.4\%) occurring as complication (Onyeagwara et. al, 2014), while da Lilly-Tariah and Somefun reported a higher incidence of CSOM 42.4\% (da Lilly Tariah and Somefun, 2007).

In our series, conservative medical management (masterly inactivity) was employed in all the cases. The ear was kept dry and the patients were told to prevent water from entering the affected ear (Toner and Kerr, 1997; Onyeagwara et al, 2014). However, none of our patient had surgical management; this was mainly due to poor facilities and expertise.

In our series, only $40.00 \%$ of cases had healed tympanic membrane after one month of treatment. This differs from the findings of Onyeagwara et al., who reported more spontaneous healing (49.7\%) (Onyeagwara et. al, 2014). Not only that, Chun et al., in Korea reported $76 \%$ spontaneous healing with a mean duration of 22.1 days (Chun et al., 1999). da Lilly-Tariah and Somefun, reported $29.3 \%$ spontaneous healing within 3 weeks (da Lilly Tariah and Somefun, 2007) in Port Harcourt Nigeria.

\section{CONCLUSION}

Traumatic perforation of the tympanic membrane is still common in our environment. Slaps and injudicious use of cotton buds ranked highest as etiological factors. Prompt diagnosis, the provision of appropriate facilities, expert management and public enlightenment campaigns to educate the public on how to prevent traumatic 
046 J. Med. Med. Sci.

membrane perforations will help reduce the morbidity associated with this condition.

\section{REFERENCES}

Afolabi OA, Aremu SK, Alabi BS, Segun-Busari S (2009).Traumatic Tympanic Membrane perforation; Anaetiological profile, BMC Res. Notes.2009, 2:232

Benitez JT (1988). Otopathology of Egyptian mummy Pum II: final report. J Laryngol Otol. 102(6):485-490

Chun SH, Lee DW, Shin JK (1999). A clinical study of traumatic tympanic membrane perforations. Korean J. Otolaryngol Head Neck Surg. 42(4):437-441.

da Lilly-Tariah OB, Somefun AO (2007).Traumatic perforation of the tympanic membrane in Uni. PH. Teach. Hosp. PH. Niger. Niger Postgrad Med. J. 14(2):121-4.

Dawood MR (2015). Spontaneous healing of Traumatic Tympanic Membrane Perforation.Mustansiriya Med.J. 14(1):24-28.

Dursun E, Dogru S, Gungor A, Cincik H, Poyrazoglu E, Ozdemir T.(2008). Comparison of paper-patch, fat, and perichondrium myringoplasty in repair of small tympanic membrane perforations. Otolaryngol Head Neck Surg.138(3):353-356
Lerut B, Pfammatter A, Moons J, Linder T (2012). Functional correlations of tympanic membrane perforation size. OtolNeurotol. 33(3):379-86.

Onyeagwara NC, Okhakhu AL, Braimah OE (2014). A retrospective study of traumatic tympanic membrane perforation at the Uni. Benin Teach. Hosp. Nigeria. Ann. Biomed. Sci. 13, No 1.

Orji FT, Agu CC (2008).Determinants of spontaneous healing in traumatic perforations of the tympanic membrane. ClinOtolaryngol. 33(5):420-6.

Salim HA (2009). Spontaneous healing of traumatic perforations of the tympanic membrane. Ann. Coll. Med. Mosul; 35: 26-32.

Sarojamma, SR, Satish HS (2014). A Clinical Study of Traumatic Perforation of Tympanic Membrane. J. Dent. Med. Sci. 13(4):24-28.

Toner JG, Kerr AG (1997). Ear Trauma. In: Scott-Brown's Otolaryngology. Otology. 6. Booth JB, Kerr, Advisory AG, Groves J, editor. Butterworths Meinemann, London. 3/711-3/7/13.

Zheng CL, Zi HL, Qing PZ (2012). Traumatic tympanic membrane perforations: a study of etiology and factors affecting outcome. Am. J. Otolaryngol; 3: 549-555. 


\section{PROFORMA}

1. BIODATA

DATE...

Serial no

Age.....

Gender....

Religion...

Occupation....

2. CLINICAL PRESENTATION

i..............

ii.....

iii..............

3. TIME SPENT BEFORE PRESENTATION

4. OTOSCOPIC FINDINGS (OTOSCOPY WAS DONE BY BOTH SENIOR RESIDENTS AND CONSULTANT) LEFT EAR

\section{RIGHT EAR}

i..........

iil..........

iii.........

i...........

iii.......

5. CLINICAL DIAGNOSIS

6. PURE TONE AUDIOMETRIC FINDINGS

\begin{tabular}{|c|c|}
\hline LEFT EAR & RIGHT EA \\
\hline i.......... & i........... \\
\hline & iii....... \\
\hline
\end{tabular}

7. SOURCE OF INJURY TO THE EAR

i.......

ii..........

iii.........

8. COMPLICATIONS ASSOCIATED WITH THE INJURY

i.......

ii..........

iii........

9. TREATMENT PRIOR TO PRESENTATION IN THE HOSPITAL

YES.... NO..., IF YES; WHERE WAS THE TREATMENT CARRIED OUT?

10. MANAGEMENT OF TYMPANIC MEMBRAE PERFORATION/OUTCOME

Conservative medical

Surgical

i........

ii.........

iii......

ii.......

iv..........

iii.....

OUTCOME

iv........

(i) those that achieved complete healing........

(ii) those that did not achieved good healing........

(iii) those lost to follow up.............

ANY OTHER OBSERVATIONS. 